spinozista de liberdade - como auto-determinação - reflete, justamente, o fato de neste último o conatus não poder ser entendido apenas a partir do princípio de inércia, remetendo a uma "essência". Como diz Chauí, "a definição do conatus como esforço de manutenção da proporção interna para vencer as forças externas e adversas [grifo nosso] e para compor com elas, quando concordantes com a essência e potência individuais, revela que a noção de conflito não pode ser circunscrita à relação com o exterior, mas deve também ser encontrada no interior de cada indivíduo complexo" (Chauí 3, p. 308).

26. O hilozoísmo - literalmente, "matéria animada" - pode ser compreendido como uma concepção pela qual o universo inteiro seria uma coisa viva. Podemos encontrar esse princípio em diversos autores antigos, como em Heráclito e nos estóicos. Spinoza claramente abraça esta concepção, que, de certa forma, inverte a visão da ciência moderna: os seres vivos não devem ser entendidos como "seres inanimados complexos", mas, ao contrário, os objetos comuns é que seriam "seres vivos simplificados". É assim que, nos Pensamentos Metafísicos, Spinoza afirma que "entendemos, pois, por vida a força pela qual as coisas perseveram em seu ser, e, como essa força é distinta das próprias coisas, dizemos propriamente que as coisas têm vida. Mas como a força pela qual Deus persevera em seu ser nada mais é do que sua essência, falam bem aqueles que dizem que Deus é a vida" (Spinoza 15, CM, II, 6, p. 30). No escólio da proposição II-13 também vemos que não só os homens, mas todos os indivíduos, ainda quem em graus variados, são animados (Spinoza 13, EII, P13, S, p. 97). Curley comenta que "I believe Spinoza does really think it appropriate to conceive of all things as living” (Curley 4, p. 73; Cf. Bennet 2, p. 138).

\section{SOBRE A DEFINIÇÃO DE DEMOCRACIA NO TRATADO} TEOLÓGICO POLITICO

André Menezes Rocha*

Resumo: Este texto examina, com brevidade, o sentido definição de democracia no capítulo 16 do Tratado Teológico-Politico. Num primeiro momento, faço uma pequena história dos estudos, no século passado, acerca da forma do discurso político do TTP. Em seguida, passo à interrogação do sentido da definição de democracia e da lógica geométrica que estrutura o discurso político de Espinosa. Com fundamento no décimo sexto capítulo, podemos dizer que a essência da democracia é anterior tanto ontológica como históricamente às essências dos outros regimes e que esta anterioridade, no caso do exame da história hebraica, também é cronológica. Isso pode significar que, desde o Tratado TeológicoPolitico, toda a política de Espinosa está fundamentada na definição da essência da democracia.

Palavras-chave: discurso, política, definição, democracia, poder.

Desde a tese de Leo Strauss sobre a maneira de ler o Tratado Teológico-Político de Espinosa, os estudiosos discutiram muito pouco a forma do discurso político de Espinosa. Quero chamar a atenção sobre o estudo de Strauss, pois é com ele que a forma do discurso político de Espinosa começa a ser interrogada.

Strauss examina a distinção estabelecida por Espinosa entre as regras necessárias à exegese de livros inteligíveis e de livros hieróglifos. A distinção foi estabelecida por Espinosa no capítulo 7 do Tratado Teológico Político [TTP], capítulo em que apresenta as regras que elaborou para a interpretação das Escrituras. Strauss argumenta que a distinção e as "regras hermenêuticas" apresentadas por Espinosa não servem para interpretar o $T T P^{l}$ e que para este propósito ele, Strauss, apresentará as regras. ${ }^{2}$ Quais são as regras? Strauss recorre à distinção entre a apresentação "exotérica (ou aberta) e a apresentação esotérica (ou enigmática)" (Strauss 7, Página. 237) que segundo ele também foi usada por Descartes e Hobbes, cuja formulação moderna e recomendação se encontrava numa passagem do Advancement of learning ${ }^{3}$ de Bacon. De maneira sumária,

* Doutorando USP. 
a chave de leitura do TTP se encontra, para Strauss, nesta distinção. Cumpre observar que Strauss se dedica, no que se refere aos conteúdos, ao exame dos capítulos do TTP voltados às questões teológicas. Debalde o leitor encontrará um exame, por exemplo, do capítulo 16 do TTP, embora seja possível encontrar conclusões políticas do exame da teologia no texto de Strauss.

Entre os comentadores posteriores que se dedicaram ao conteúdo da política do TTP, por sua vez, encontramos poucos que consideram a questão da forma do texto como importante para a compreensão do TTP. Não queremos com isto dizer que pouco foi feito entre 1952 e os dias atuais. Certamente houve avanços consideráveis no campo dos conteúdos de certas teses características do discurso político de Espinosa. Aqui frisamos é que poucos estudiosos questionaram seriamente a tese de Strauss sob a forma da escrita e a maneira de interpretá-la.

Podemos mencionar a leitura da política de Espinosa de Matheron, concentrando na inovação que trouxe, sobretudo, para o leitor do TTP. Publicada em 1968, a leitura de Matheron (Matheron 6) é um marco, na medida em que mostra a singularidade de Espinosa pelas diferenças em relação a Hobbes. Concentremo-nos, por exemplo, na questão da transferência de potência dos indivíduos para a república, ou seja, na questão da gênese da política, questão nuclear no capítulo 16 do TTP. “ $A$ transferência, se transferência existe, torna-se então algo de muito simples e banal: a efetuamos cotidianamente." (Matheron 6, P 295 e 296). A transferência de potência dos indivíduos para a república deixa de ser pensada como um acontecimento instantâneo no passado e passa a ser pensada como fundamento permanente da política: deixa de ser pensada segundo a causa final, como nas teorias aristotélicas, mas também deixa de ser pensada segundo a causa eficiente transitiva, como na teoria hobbesiana, e passa a ser pensada segundo a causa eficiente imanente, tese legitimamente espinosana. Entretanto, Matheron, talvez por tratar também da Ética e do Tratado Político em seu estudo, não indagou a peculiaridade da forma do discurso político do TTP.

Apenas em 1985 surge novamente a discussão com a publicação de um artigo de Fokke Akkerman. Neste artigo, Akkerman sustenta que a forma do TTP é predominantemente retórica. Existem, certamente, definições e raciocínios que exigem do leitor reconhecer diferenças de estilo: “... o estilo do TTP é sensivelmente diferenciado segundo diversos métodos de raciocínio aplicados pelo autor ..." (Akkerman 3, P.381). Examinando o capítulo 12, por exemplo, Akkerman encontra dois métodos: "o método racionalista, dedutivo, e o método empírico, indutivo." (Akkerman 3, p. 382). Mas esta parte racionalista não é fundada em noções claras e distintas, porém em noções veiculadas pela tradição clássica e aceitas pelos seiscentistas que foram educados no humanismo. Em última análise, assim, de acordo com Akkerman, o TTP segue a retórica aristotélica e se funda nas opiniões aceitas pelos leitores cultivados para, partindo destas opiniões, persuadi-los.

A tese de Leo Strauss, dispensando qualquer indagação acerca de fundamentos lógicos do discurso, levou-o a supor que a chave de leitura do texto estava em buscar duas camadas de sentido: uma esotérica, oculta e só decifrável por sábios, outra exotérica, explícita e feita para coincidir com a opinião do vulgo. Existem, até onde sei, dois estudos que questionaram as teses de Strauss acerca da forma do discurso do TTP e da chave de sua leitura.

Chantal Jaquet contestou a tese de Strauss argumentando que “... $a$ chave de leitura dos textos espinozistas não repousa na oposição entre um sentido esotérico, confuso e escondido, de um lado, e um texto exotérico, claro e aparente, de outro, mas na distinção entre os ensinamentos que se fundam na razão e os que se fundam na experiência, sem, no entanto, se contradizer." (Chantal Jaquet 5, P.11). Chantal Jaquet também se apóia no capítulo sétimo do TTP, ou seja, quando fala em experiência fala em "história da natureza [historia naturae]". No entanto, para ela, à diferença de Strauss, há também no TTP certas linhas argumentativas que se fundam em ensinamentos da razão, como os livros inteligíveis de filosofia inspirados nos Elementos de Geometria de Euclides.

Em 2003, Marilena Chaui publicou Política em Espinosa e avançou decisivamente no estudo tanto da forma como do conteúdo do discurso. No que concerne à forma do $T T P$, há um capítulo dedicado exclusivamente a ela e a sua novidade é patente. Não apenas indica que há linhas argumentativas diversas que se entrecruzam no texto, algumas linhas características de livros hieróglifos e outras características de livros inteligíveis, mas ensina como interpretá-las. No caso das linhas inteligíveis, fundam-se em definições e a teoria política, no capítulo 16 de Espinosa, não é senão a construção de 
uma definição. "Em outras palavras, assim como os seis primeiros capitulos constroem a definição real do objeto 'religião revelada'o capítulo XVI constrói a definição real do objeto imperium; e, assim como o primeiro objeto conduziu à necessidade do método exegético, o segundo conduzirá à dedução puramente racional dos fundamentos do poder político." (Chaui 4, P.32). Cabe observar, na citação acima, que a dedução do poder político é racional, ou seja, fundamentada numa definição real. Isto quanto à forma, não ao conteúdo do discurso. Pois, do ponto de vista do conteúdo, somente a passionalidade dos homens explica a gênese da política. ${ }^{4}$ Do ponto de vista da forma, o texto do capítulo 16 é uma dedução racional a partir de uma definição. Ora, há geométrica política nesta dedução e, caso a resposta seja afirmativa, como ela se articula com a experiência consignada pelos historiadores romanos e hebreus? Aprofundemos esta questão.

O Tratado Teológico-Político apresenta, em seus cinco capítulos finais ${ }^{5}$, um discurso voltado para a política. Nos quinze capítulos iniciais, o discurso se volta para temas teológicos, para temas filológicos ou de exegese das Escrituras e para a questão da distinção entre a teologia e a filosofia. A apresentação, no capítulo 16, de um tratamento filosófico da política sucede à distinção entre a teologia e a filosofia, distinção operada no capítulo anterior, o décimo quinto--

O capítulo 16 tem o seguinte título: "Dos fundamentos da república; do direito natural dos indivíduos e do direito dos poderes soberanos [summarum potestatum]"6. Construção da definição real do objeto imperium ${ }^{7}$, como vimos acima na passagem de Marilena Chaui, constitui a condição para a exegese dos capítulos seguintes. Com efeito, nos capítulos 17 e 18, Espinosa examina, à luz da definição construída no capítulo 16, exemplos da história dos Romanos, sobretudo nos Anais e nas Histórias de Tácito, e da história dos Hebreus, sobretudo nas Sagradas Escrituras e nas Antiguidades Judaicas de Josefo.

Do ponto de vista do conteúdo, a história dos romanos e dos hebreus mostra que a forma monárquica enfraquece o corpo político e deixa-o vulnerável: a concentração de poderes nas mãos de Augusto, no caso dos romanos, preparando a ruína futura, bem como a transformação do regime descentrado dos Juízes em regime de concentração nas mãos dos Reis, no primeiro imperium dos hebreus que foi devastado justamente sob o domínio dos monarcas. A experiência ensina que a concentração de poderes que caracteriza a monarquia é a fraqueza que prepara a destruição do corpo político. A história dos Romanos e a história dos Hebreus, assim, são dados da experiência que podem testemunhar contra a monarquia e em favor da democracia. A tese de que a concentração de poderes no monarca enfraquece o corpo político e prepara a sua destruição surge no exame da história dos hebreus e dos romanos, ou seja, a experiência consignada nos registros historiográficos é que o mostra.

Do ponto de vista da forma, contudo, qual é a relação entre a definição construída do capítulo 16 e os exemplos históricos que são examinados à sua luz nos capítulos 17 e 18 ?

No capítulo 16, fundamentado na definição, a tese que ressalta é a afirmação de que a democracia é o "mais natural" dos regimes políticos: caso identifiquemos o "mais natural" com "mais potente", ou seja, como mais propício à conservação na existência do corpo político, como convém a este jusnaturalismo espinosano que identifica o direito natural com a potência, podemos afirmar que critério de diferenciação entre os regimes não é senão a maior ou menor potência de conservação do corpo político e a monarquia é o mínimo que, portanto, deixa o corpo político fraco e vulnerável. Mas este critério de diferenciação oferecido no capítulo 16 opera no estudo que Espinosa faz, no capítulo 17, da experiência consignada nas histórias de Romanos e Hebreus?

A relação entre a definição construída no capítulo 16 e os exemplos históricos dos capítulos seguintes pode ser intrínseca ou extrínseca. Extrínseca, se a definição espinosana não permitir demonstrar o ensinamento que a história singular de hebreus e romanos ensina. Intrínseca, se as propriedades deduzidas da definição espinosana puderem servir para demonstrar, ou seja, pensar as causas necessárias, das experiências relatadas pelos historiadores. ${ }^{8}$

Nossa hipótese interpretativa é de que a relação é intrínseca, ou seja, defendemos que a definição do capítulo 16 permite deduzir a causa necessária da fraqueza da monarquia, na medida mesma em que define a causa necessária da força da democracia, ou seja, o motivo pelo qual é o "mais natural". Em apoio a esta hipótese, examinemos um trecho do capítulo 16.

Após definir o direito natural pelo conatus, ou seja, pela potência individual de autoconservação, bem como dele deduzir a gênese do Estado [imperium] pela célebre e controversa teoria do pacto social, Espinosa adverte o leitor de que não tratou de todo e 
qualquer imperium, mas somente do democrático.

"Julgo ter mostrado com bastante clareza os fundamentos do Imperium Democrático, de que preferi tratar porque me parece o mais natural ${ }^{9}$ e que mais permite a liberdade que a natureza concede a cada um. Pois nele ninguém transfere seu direito natural a outro de maneira que depois [in posterum] nunca mais seja consultado, mas transfere à maior parte de toda a Sociedade de que participa. Por isto é que todos permanecem desta maneira iguais, como antes no estado natural [in statu naturali].”(Espinosa 1, p.195) ${ }^{10}$

A preferência pela democracia poderia ser explicada somente por um critério político, qual seja, a decisão espinosana de apoiar uma política da liberdade contra uma política que torne os homens servos, entre outras coisas, pela censura e pelo controle do saber. Poderíamos encontrar fatores extrínsecos ao texto que concorreriam pela explicar este critério: por exemplo, Espinosa viver e escrever numa Holanda republicana com relativa liberdade ideológica e econômica, se comparada às monarquias absolutistas que, como na Espanha e na França, suprimiam as liberdades civis tendo em conta outras finalidades políticas.

Entretanto, o texto espinosano, qualificando a democracia de "mais natural", nos remete a fundamentos estabelecidos anteriormente e não a critérios extrínsecos. Com efeito, neste mesmo capítulo 16 , a definição do conatus, que precede e condiciona a demonstração da gênese do imperium democrático, exclui qualquer causa final: nenhum indivíduo, com efeito, existe tendo como finalidade conservar a existência de um outro, mas cada um existe para conservar sua própria existência. Ora, no imperium democrático, como escreveu Espinosa no trecho que acima citamos, ninguém transfere seu direito a outro, mas cada um e todos à sociedade. A transferência de seus direitos naturais, motor da gênese do imperium, não é alienação a outro, ou seja, não é consentir em obedecer outros homens, pois transferir seu direito natural para a sociedade é consentir em obedecer às leis civis. Por isto é que ninguém obedece a outros, porque todos obedecem às leis civis, porque não há alguns que se isentam da obediência às leis civis e obrigam outros a obedecer a seus caprichos pessoais. Entre o estado natural e o imperium democrático, portanto, existe uma maneira de transferir a potência individual para a sociedade. A definição de conatus, excluindo as causas finais e restringindo a política à busca das causas eficientes imanentes, consiste num critério, intrínseco à própria filosofia de Espinosa, que pode ser suficiente para explicar a preferência pela democracia. $\mathrm{O}$ imperium democrático tem precedência ontológica e lógica ante os demais? Espinosa parece sugerir que podem ser deduzidos da democracia.

"Deixo de lado os fundamentos das soberanias dos demais [relinquarum potestatum] e nem nos é preciso [opus est] agora conhecer o seu direito, de onde tiveram [unde ortum habuerint] e freqüentemente têm sua origem: com efeito, isto consta com bastante clareza do que já mostramos." (Espinosa 1, p.195) $)^{11}$

A origem do imperium aristocrático e do imperium monárquico, portanto, está implícita naquilo que já foi demonstrado e cabe aos leitores torná-la explícita de acordo com as premissas assentadas no texto. Mas, como observamos, neste capítulo 16 só foi demonstrada a gênese da democracia. Assim, Espinosa parece indicar que a democracia tem uma anterioridade ao menos lógica face aos outros regimes.

Se o capítulo 16 constrói a definição do poder político tomando a democracia como anterior ontológica (o mais natural ou mais potente) e logicamente (o conceito de democracia é condição para formar os conceitos de aristocracia e monarquia), então permite concluir, neste plano puramente racional, que a monarquia é o menos potente, ou seja, que a concentração de poderes da monarquia deixa o corpo político vulnerável.

Algumas conclusões importantes decorrem desta interpretação:

(1) Do ponto de vista da forma e do conteúdo, o capítulo 16 do TTP constrói a definição do poder político de maneira geométrico-filosófica e, por isso, podemos dizer que é um texto inteligível ou um "livro inteligível”. A tese de Leo Strauss sob a forma do TTP assim, se mostrará insuficiente, pois leva a supor oculto um ensinamento que Espinosa, no capítulo 16, oferece aberta e publicamente não ao vulgar, mas ao leitorfilósofo instruído na geometria. 
(2) Em segundo lugar, a anterioridade ontológica e lógica da democracia permite examinar sob nova luz qual é a relação entre a definição no capítulo 16 e a experiência de Romanos e Hebreus acerca da monarquia que precedeu a sua aniquilação, ensinamento assinalado por Espinosa no capítulo 17. No caso dos Hebreus, com efeito, há trechos do capítulo 17 indicando que a democracia tem precedência lógica e cronológica face às outras formas políticas. ${ }^{12}$

\section{REFERÊNCIAS BIBLIOGRÁFICAS}

1. SPINOZA, BENEDICTUS DE. Opera. Im Auftrag der Heidelberger Akademie der Wissenschaften hrs. von Carl Gebhardt. Heidelberg : C. Winter, [c1972], 4 volumes.

2. ESPINOSA, BARUCH DE. Tratado Teológico-Político. Tradução, introdução e notas de Diogo Pires Aurélio. Estudos Gerais, Série Universitária, Clássicos de Filosofia. Lisboa: Imprensa Nacional - Casa da Moeda, 2004. 3. ed., integralmente revista.

3. AKKERMAN, FOKKE. Le caractère rhéthorique du TTP. Cahiers de Fontenay, Fontenay-aux-Roses, no 36 a 38, mars 1985, p.381-390.

4. CHAUI, MARILENA DE SOUZA. Política em Espinosa. São Paulo: Companhia das Letras, 2003.

5. JAQUET, CHANTAL. Spinoza ou la prudence. Paris, 2004.

6. MATHERON, ALEXANDRE. Individu et communauté chez Spinoza. Nouvelle Édition. Paris: Editions de Minuit, 1988.

7. STRAUSS, LEO. Le testament de Spinoza. Textes traduits et annotés par Gérard Almaleh, Albert Baraquin, Mireille Depadt-Ejchenbaum. Paris: Les Editions du Cerf, 1991.

\section{On the definition of democracy in the Theological-Political Treatise}

Abstract:: This paper examines briefly the meaning of the definition of democracy in Chapter 16 of the Theological-Political Treatise. At first, I make a little history of the studies made in the last century concerning the way in which Spinoza wrote his political discourse. Then, I will treat the question around the geometric logic that structures Spinoza's political discourse and defines the essence of democracy. According to the sixteenth chapter, we can say that the essence of democracy is both ontological and historically prior to the essences of other systems and that this priority, for the examination of Jewish history, is also chronological. This may mean that after the Theological-Political Treatise the whole politics in Spinoza is based on the definition of the essence of democracy.

Keywords: discourse, politics, definition, democracy, power.

\section{NOTAS}

1. "Nosso estudo das regras de leitura de Espinosa parece nos ter conduzido a um impasse. Nós não podemos ler seus livros como ele leu a Bíblia, porque certamente seus livros não são livros hieróglifos. Tampouco podemos ler como ele leu Euclides e outros livros inteligíveis, dado que os livros de Espinosa não nos são tão inteligíveis como eram para ele os livros não hieróglifos que ele conhecia.”. (Strauss 7, p.201).

2. "Nós vimos como julgar o pensamento predominante da época presente à luz de princípios de Espinosa ou como é possível, permanecendo estritamente fiel a seus princípios, dar um sentido mais largo à concepção dos obstáculos que se impõem à filosofia e, portanto, à interpretação dos próprios livros de Espinosa. Adquirimos, assim, o direito de abandonar as regras que Espinosa elaborou para a leitura de seus livros. Mas ao mesmo tempo nos damos conta de que não podemos simplesmente substituir suas regras de leitura por aquelas que são efetivamente utilizadas por muitos dos historiadores modernos. ". (Strauss 7, p.210).

3. Para a referência à passagem de Bacon, consultar esta mesma página 237 que citamos na nota anterior. Nesta mesma página o leitor encontrará as referências de Strauss a Descartes e Hobbes, mas também encontrará referências ao uso desta mesma arte de escrita (que opera com camadas esotéricas e exotéricas) em Maimônides e Platão.

4. Espinosa tem um argumento que é usado tanto no Tratado Teológico-Politico como no Tratado Político para demonstrar que a construção das instituições políticas só pode ser explicada pela natureza passional dos homens. O argumento é uma prova por absurdo. Se os homens vivessem segundo os ensinamentos da razão, as instituições políticas não seriam necessárias. (Espinosa 1,p.73) "Se já agora os homens estivessem constituídos pela natureza de tal maneira que não desejassem nada além do que a verdadeira razão indica, a sociedade não careceria de leis, pois seria suficiente ensinar aos homens ensinamentos morais verdadeiros para que com ânimo integro e liberal espontaneamente fizessem aquilo que é verdadeiramente útil. Na verdade, algo outro está constituído [constitutum est] com a natureza humana. Todos, com efeito, procuram seu útil, mas minimamente pelo ditame da razão, pois quase tudo apetecem e julgam útil pelos excessos dos apetites e arrastados pelos afetos do ânimo (sem levar em conta o tempo futuro ou as causas das coisas).". No Tratado Político, a referência é a seguinte: TP6/3. Este terceiro parágrafo 
do sexto capítulo do Tratado Político parece uma reprodução deste trecho do Tratado Teológico-Político que acabamos de citar. No capítulo 16 do TTP, que nos interessa aqui, a referência é TTP16, SO3, p. 190 (13-14).

5. Do capítulo 16 ao capítulo 20.

6. "De Reipublicae Fundamentis; de jure uniuscujusque naturali \& civili: deque Summarum Potestatum Jure".

7. Os comentadores de Espinosa têm muitas dificuldades com tradução de seu vocabulário político. Este vocábulo, imperium, comumente é traduzido por Estado. Preferimos manter o termo latino.

8. No caso do Tratado Político, a ordem de exposição dos regimes (monarquia, aristocracia, democracia) é a ordem lógica do mais fraco ao mais forte, ou seja, do menos capaz de conservar o corpo político ao mais capaz. Esta ordem lógicogeométrica é utilizada, no Tratado Político, para a exegese de exemplos históricos, como o absolutismo espanhol e o imperium do "Grande Turco". Pensando este exame, Marilena Chaui escreve: “Assim, a experiência confirma a geometria não porque mostre, na região dos dados, aquilo que está sendo deduzido na região das idealidades, mas porque, ao trazer os fatos, deixa entrever que o percurso da forma política na duração histórica confirma o percurso geometricamente demonstrado, sem que os agentes históricos cheguem a ter plena consciência desse processo. A experiência confirma a geometria menos porque os fatos corresponderiam às idéias e muito mais porque as leis da vida política se manifestam nela e essas leis são o objeto da geometria política.”. (Marilena Chaui 4, Página 227). Podemos encontrar no Tratado Teológico-Político esta geometria política que permite pensar o percurso da duração histórica de formas políticas singulares? Penso que a construção da definição de poder político no capítulo 16, estabelecendo a anterioridade ontológica e lógica da política, permite afirmar, como buscarei indicar nas considerações que seguem no corpo do texto.

9. Grifo meu.

10. Tradução minha. Segue original para comparações."Atque his imperii democratici fundamenta satis clare ostendisse puto; de quo prae omnibus agere malui, quia maxime naturale videbatur, \& maxime ad libertatem, quam natura unicuique concedit, accedere. Nam in eo nemo jus suum naturale ita in alterum transfert, ut nulla sibi imposterum consultatio sit, sed in majorem totius Societatis partem, cujus ille unam facit. Atque hac ratione omnes manent, ut antea in statu naturali, aequales.".

11. Tradução minha. Segue o original para comparações. "Reliquarum ergo potestatum fundamentis supersedeo, nec nobis, ut earum jus noscamus, scire jam opus est, unde ortum habuerint, \& saepe habeant; id enim ex modo ostensis satis superque constat."

12. Cito o trecho em que, examinando a história dos Hebreus no momento do Êxodo, ou seja, antes da fundação do Templo em Canaã, Espinosa identifica a primeira transferência dos indivíduos para Deus, que elegeram seu soberano antes de Moisés, com a transferência de potência que foi teorizada pela teoria do pacto social no capítulo 16. Observe, assim, a coincidência entre este princípio cronológico (descrito no livro do Êxodo) e o princípio ontológico e lógico (contido na definição construída pelo capítulo 16). (Espinosa 1, página 205). "Atque haec promissio, sive juris in Deum translatio eodem modo facta est, ac in communi societate supra concepimus fieri, quando homines jure suo naturali cedere deliberant. Expresse enim pacto (vide Exod. cap. 24. vers. 7.) \& juramento jure suo naturali libere, non autem vi coacti, neque minis territi cesserunt, \& in Deum transtulerunt.”. Há outra referência próxima a este mesmo trecho, em que Espinosa nomeia expressamente a democracia como princípio. (Espinosa 1, página 206). 